As far as the benefits of using resources in this way are concerned they are alleged to be incalculable. One possible calculation, however, is to compare the benefits that would be derived from using the resources in some other way-that is to compare the costs and benefits of alternative ways of extending life and improving its quality. The use of computed tomography or any other procedure consumes resources which cannot then be used to confer benefits on other patients, and these potential benefits should also be taken into account.

Until the appropriate calculations have been carried out no conclusions should be drawn about the resource implications of medical procedures. Your leading article on expensive medical techniques (5 February, $p$ 417) pointed out that proper clinical trials are the only way to assess new medical procedures, including those of diagnosis. We would go further and suggest that the same scientific rigour applied to establishing clinical effectiveness should be applied to economic appraisal. The efficiency with which scarce NHS resources are used would be improved if more consideration were given to such issues.

ANNE LUDBROOK

DAVID PARKIN

Health Economics Research Unit,

University of Aberdeen
Aberdeen AB9 2 ZD

\section{Cost of anaesthesia}

SIR,-We note with interest the article by Dr B A Astley and Dr J Secker Walker on the "Cost of anaesthesia" (17 July 1982, p 189) and Dr M Heath's reply (25 September, p 891). Perhaps the following observations and suggestions may enable many cost conscious anaesthetists or administrators to reduce their total budget by 1 to $2 \%$ without reducing the numbers of staff employed. This can be simply effected to the advantage of the patient, anaesthetist, and surgeon.

Since medical and ancillary staff salaries will always use up the largest part of any budget and cannot be altered unless a unit is overstaffed, economy must come from the remaining $15 \%$ of the budget (to use the figures quoted). Drugs constitute over $50 \%$ of the remaining costs. Of these, nitrous oxide, halothane, and ethrane account for $35 \%$ of our total drug bill at a cost of $£ 13387$ per annum. In many hospitals the cost of these three drugs can probably be reduced by as much as, or more than, half. We have noticed that breathing systems delivering anaesthetic gases and vapours are often used with inappropriately high flows, even allowing for a margin of safety. For instance, the fresh gas flow used with a Magill system is often set at 6 to $8 \mathrm{litres} / \mathrm{min}$ (4 to 5 litres $\mathrm{N}_{2} \mathrm{O}$ with 2 to 3 litres $\mathrm{O}_{2}$ ) for all patients irrespective of their mass. In some hospitals it is the practice to use the Bain system for both controlled and spontaneous respiration. Despite requiring three times the fresh gas flow during spontaneous respiration than more efficient systems, ${ }^{1}$ the Bain is used merely for its convenience as a single system for all patients whether for spontaneous or controlled ventilation.

Newer systems are now available which function more efficiently than their traditional alternatives ${ }^{12}$ and offer a solution to the practice of using a single system for spontaneous and controlled ventilation. Recent studies have shown the I-ack system, a modified Mapleson A system (Medical and Industrial Equipment Ltd, Exeter, Devon) to be the most appropriate for spontaneous respiration. ${ }^{1}$ It uses about $30 \%$ less fresh gas flow than the Magill, a mean flow of 3.6 litres $/ \mathrm{min}$ being required for a $70 \mathrm{~kg}$ man. At this flow rebreathing is not induced, and it does not rely on carbon dioxide absorption.
Thus gas flows can be virtually halved. Since the Lack system offers scavenging facilities at the machine end, the problem of theatre pollution can be virtually eliminated, to the benefit of all operating theatre staff. It is also likely that inspired humidity levels are higher, to the benefit of the patient, ${ }^{34}$ The Lack system, however, can be used efficiently only for spontaneous respiration. During controlled ventilation the Bain system offers considerable advantage,${ }^{5}$ but its convenience can no longer serve as an excuse for its use during spontaneous respiration. A new simple system incorporating the advantages of both the Lack system for spontaneous and the Bain system for controlled ventilation has been developed (Anaesthetic Breathing System Supplies, Shrewsbury, Shropshire), and can be used in the Mapleson A, $\mathrm{D}$, or $\mathrm{E}$ mode depending on the mass of the patient and the method of ventilation. It can also be used as a "valveless Mapleson A" system, reducing by half the flows necessary when anaesthetising spontaneously breathing children with the $T$ piece. Whether for adults or children for spontaneous or controlled ventilation, the "ADE" system is estimated to use a fresh ga flow of no more than an average of 4 litres/min.

Advocates of the closed circuit carbon dioxide absorption technique with minimal flows may suggest that costs can be much further reduced. Nunn concluded, however, that there was only very weak case for the benefits of low flows with the circle absorber versus the additional difficulties of the technique. ${ }^{6} \mathrm{He}$ noted that fresh gas flow of 4 litres/min seemed to be more usual in the USA (these flows being used to circumvent the difficulties). With the new "ADE" system a much the same flow, inspired oxygen, nitrous oxide, and vapour tensions are as set by the anaesthetist, while normal arterial carbon dioxide levels are as predictable as for the Bain system. Without sophisticated monitoring apparatus or complicated mathematical formulae the closed circle absorber does not offer these advantages. The circle is also far more bulky and prone to leaks, while nitrogen washout and soda lime exhaustion add two more points for the anaesthetis to consider.

It is therefore not surprising that many anaesthetists prefer to use "non-rebreathing" systems which are simpler, safer, and behave more predictably. Substantial savings can now be made, however, by the appropriate and correct use of the best "non-rebreathing" system available.

D HUMPHREY

J W DOWNING

Departments of Physiology and J G BROCK-UTNE

Departments of Physi
Anaesthetics,
University of Natal,
Congella 4013, Natal,
South Africa

${ }^{1}$ Humphrey D. The Lack, Magill, and Bain anaesthetic breathing systems: a direct comparison in spontaneously-breathing anaesthetized adults. $\mathcal{F} R$ Soc Med 1982;75:513-24.

${ }^{2}$ Humphrey D. A new anaesthetic breathing system combining Mapleson A, D, and E principles: cimple apparatus for low thow universal use without carbon dioxide absorption. Anaesthesia (In press). Fynn PJ, Morris LE. Humidity
systems. Br $\mathcal{F}$ Anaesth 1981:53:1096.

4 Chalon J, Chandrakant P, Mahgul A, Ramanathan S, Capan L, Chau-Kvei T, Turndorf H. Humidity and the anaesthetised patient. Anaesthesiology $1979 ; 50: 195-8$

${ }^{5}$ Henville JD, Adams AP. The Bain anaesthetic system an assessment during controlled ventilation. Anaesthesia 1976;31:247-56.

anaesthesia. In: Aldrete JA, Lowe H closed circuit anaesthesia. In: Aldrete JA, Lowe HJ, Virtue RW, eds. Low flow and closed system anesthesia.
York: Grune and Stratton, 1979:109-112.

\section{Pretibial injuries: a common pitfall}

SIR,-Mr Barry M Jones and Mr Roy Sanders (12 February, p 502) assume the commonly held view of plastic surgeons that the most appropriate treatment for pretibial flap lacerations is radical excision and split skin grafting-preferably with the patient admitted for elevation of the leg and nursing supervision. In my view this approach represents overtreatment, for studies carried out in accident and emergency departments have shown that uniformly good results can be obtained by nurses or doctors following a regimen for conservative treatment on an outpatient basis.

Aseptic wound toilet with saline removes blood clots underlying the flap so that closure by adhesive skin strips can be achieved without tension-a gap of one strip should be left between adjacent closures. If the wound edges cannot be completely approximated a small area is left to granulate. Gauze squares are placed over the wound and the limb enclosed in a six inch crêpe bandage. The patient is encouraged to resume normal activity but is advised when resting to elevate the leg above the horizontal position. (Viscopaste bandaging as advocated by Crawford and Gipson ${ }^{1}$ does not appear to confer any additional advantage.)

The multicentre study reported to the international congress of emergency surgery held at Brighton in 1981 examined 180 pretibial injuries treated by this method in nine accident and emergency centres. ${ }^{2}$ Ninety-two per cent of cases achieved primary healing as defined by a closed, stable wound requiring neither support nor supervision with an average number of four return visits only. The median healing time was 25 days. This, I maintain, is a result at least comparable to that obtained with more aggressive (and patient restrictive) surgical manoeuvres. Those few patients who failed to achieve primary healing by this method would, I believe, do badly with whatever treatment method were instituted, but an analysis of the failures in terms of the aetiology has not as yet realised any predictive criteria as to which patients will not fare well by the treatment method described. Their numbers are small, however, and perhaps negligible when related to the overall success and simplicity of the technique.

It is my view that, in the first instance, conservative treatment of flap lacerations by the apposition of the flap edges with adhesive skin closures should be the method of choice in the accident and emergency department.

ANDREW K MARSDEN

Pinderfields General Hospital,

West Yorkshire WF1 4DG

Crawford BS, Gipson M. Conservative management of pretibial lacerations in elderly patients. Br $\mathcal{F}$ Plas of pretibial lacerations
Surg $1977 ; 30: 174-6$.

Marsden AK. A fresh look at "coal scuttle shin." acutely ill and injured. Chichester: J Wiley and Sons. 1982:315-7.

SIR,-Mr Barry $M$ Jones and Mr Roy Sanders rightly draw attention to the problem of pretibial injuries and suggest in their leading article (12 February, p 502) that these injuries are seen in most accident and emergency departments and are invariably recognised as one of the most difficult of soft tissue injuries to treat. Because of their nature and the factors against their rapid healing several different methods of treating such injuries have been used. It is quite true that the vast majority do occur in women over the age of 50 and the aetiology has been recognised in the term "supermarket injuries," which is commonly used to describe this type of injury. There is general agreement that suturing these lacerations is the surest way 